\title{
Designing with users to meet people needs: a teaching model
}

\author{
Laura Anselmi ${ }^{\mathrm{a},{ }^{*}}$, Marita Canina ${ }^{\mathrm{a}}$ and Elisabetta Coccioni ${ }^{\mathrm{a}}$ \\ a INDACO Deparment, Politecnico di Milano, Via Durando 38/a, 20156 Milan, Italy
}

\begin{abstract}
Being in a context of great transformations of the whole system company-product-market, design becomes interpreter of the society and strategic key-point for production realities. Design must assume an ergonomic approach and a methodology oriented to product innovation where people are the main focus of the system. Today it is visible the need for a methodological approach able to include the context of use employing user's "creative skills". In this scenario, a design educational model based only on knowledge doesn't seem to be fulfilling; the traditional "deductive" method doesn't meet the needs of new productive assets, here the urgency to experiment within the "inductive" method for the development of a method where to know and to know how, theory and practice, act synergistically. The aim is to teach a method able to help a young designer to understand people's needs and desires considering both the concrete/cognitive level and the emotional level. The paper presents, through some case studies, an educational model developed combining theoretical/conceptual and practical/applicatory aspects with user experiential aspects. The proposed approach to design enables the students to investigate users' needs and desires and helps them proposing innovative ideas and projects better fitting today's market realities.
\end{abstract}

Keywords: didactic model, user, teaching design, product design.

\section{Introduction}

Liquid modernity is the metaphor used by the sociologist Zygmount Bauman to describe the new century characterized by instability, endless changes and drifts; "...fluids flow relentlessly, you cannot stop them, they avoid any obstacle...". In the same way our modernity (just like during the transition from the $\mathrm{XX}$ century to the XXI century) is characterized by a constantly changing socio-economic-cultural context. Factors such as globalization, the growing importance of communication processes (now even faster thanks to the development of networks), technology innovation, economic crisis, emerging countries and their new roles, that we need to confront with (both on the economical and cultural side), the unpredictability of tomorrow, etc.

This is how the XXI century starts and it is with this context that design must establish a relationship, as it is easy to understand that the design scenarios have changed radically within the last 50 years.
The development of electronics, and then of computer science, throughout the eighties and nineties generated a radical change within the new product categories on their performance level and on the user-product interaction, now not only mechanical but also psycho-cognitive [2].

Design today doesn't only have the role of interpreter of the society, capable of offering appropriate answers, it becomes a strategic element for companies interested in understanding and satisfying users' requirements, tastes and needs.

Therefore, thanks to its multidisciplinary knowledge nature, an ergonomic and anthropocentric approach to design becomes the key to understand complex modernity.

In such a complex and interactive industrial system the competition is not only based on costs reductions, but also on the perceived and real products qualities.

Pushed by the market needs, companies are starting to acknowledge the ergonomic approach to design as a key factor for innovation:

*Corresponding author. E-mail: laura.anselmi@polimi.it 
- each user need becomes a business strategy to differ from the competitors and offer a surplus to the client;

- products must be designed for and answer to the users' needs. They should never require physical or psychological adaptation by the user;

- the usage quality is a fundamental requirement for a product.

The user is central and takes part to the definition of new products [18].

\section{Innovation and design}

In the discussion about the competitiveness of European economic system there is a general agreement about the importance of innovation. The whole change of the international economic scenario requires a quick update of the traditional competitive logic. The importance of social issues becomes element to strengthen the competitiveness of European economy [3].

"From the protection of the environment through eco-innovation to the improvement of individual well-being through more intelligent infrastructure provision, the Commission is convinced that innovation in a broad sense is one of the main answers to citizens' material concerns about their future".

In the Commission Staff Working Document, "Design as a driver of user-centred innovation" [4] the strong relationship between the use of design and the national competitiveness is underlined.

Nowadays, the meaning of innovation has changed: the sphere of technology and forms merges with that of meanings and experiences. Until now the relation between the physical shape and the function has ruled the theory and the practice of design, while the last decade saw a permutation towards the user and the user-experience. The expression human centered approach collects all the entries that identify similar research interests centered on the human being, and it represents the contemporary design approach mostly focused on the user experience.

The designer plays the role of merging between different aspects: technology, communication, ergonomics, user experience and aesthetic dimensions of the product.

In relation to these changes, it is clear the need for different design methods and new expressive languages able to face the extremely interactive potential of new emerging product classes linked to the development of new technologies, new materials and wearables. These changes highlight the need for an interdisciplinary team and design approach.

New instruments and investigation methods are required such as: behavioral maps and interviews to really understand user motivations, unfocus groups to let free creativity; atypical questionnaires to investigate iteration ways, aesthetical and narrative preferences and styles, etc..

In the advanced phase of the project, after brainstorming, it is suggested to realize quick models using, for example, mock up everything and create scenario, that allow to create every type of model for each user and visualize possible solutions

As Sottsass, precursor of a broad concept of design, also Josephine Green [8], senior director of Trends and Strategy at Philips Design, in his presentation on "social innovation" at the conference IIT Institute of Design Strategy, set out the concept of a new era of creativity and the growth of design.

The future does not have to be a box of technology and goods, but a place where social needs are met through a social approach that is both an opportunity and a necessity.

The design has the task to interpret and reinvent lifestyles and patterns of growth. New technologies will enable the development of radical innovations through services, and personalized context-based systems.

This dynamic change is not achievable through an incremental innovation, but only through a profound structural change: a radical innovation. Rethinking and reinventing some of the basic social sectors such as health care, education, transport, and overall lifestyles becomes the only way to face the future.

The transition from a market-oriented approach to a social-oriented approach (based on research and social innovation) and the use of co-creation methods with stakeholders/users allows the design to respond in an innovative and conscious way to the new demands of people [11].

It seems that this new approach to design is starting to be recognized, accepted and widely available all over Europe. In fact, as a very explicit quote says:

"Design for user-centred innovation is the activity of conceiving and developing a plan for a new or significantly improved product, service or system that ensures the best interface with user needs, aspirations and abilities, and allows for aspects of economic, social and environmental sustainability to be taken into account». 


\section{Exploratory learning approach}

The implementation of new technologies requires close cooperation among the various stakeholders involved. In order to have good results, starting from the improvement of technical performances to market innovation, it is necessary to involve stakeholders from different disciplines.

Design for improve life leads to the assumption of a specific design process, a method that allows a multi-disciplinary team to address the integration of different functions (safety, comfort, efficiency, etc.) in the compatible substrate.

The elements, which need to be highlighted, are the relevant interactions between the field of health and welfare, safety, legislation, ergonomics, usability, attractiveness, biomechanics and anthropometry.

In this scenario the training of the future players is obviously a strategic element leading to the achievement of a process capable of triggering new and innovative design ways.

Explaining design today means helping to understand the complex nature of modern society; therefore training in diverse disciplines traditionally not belonging to design (such as cognitive psychology, social science or computer, etc.) is extremely important. Designers have to contribute actively to the definition and evolution of the project, to the market strategy and finally to the presentation of the final product.

Therefore, the training process has to be articulated in a continuous renewal of profiles through the innovation of disciplinary contents and in accordance with the ever-changing nature of the labor market.

In Italy, for example, from the historical core elements of product design, linked to the leading sectors of the national economy, we witness a new opening of pathways related to advanced technologies, strategic design, services, communication and usability engineering.

The teaching of design in the coming years will be a well-structured theoretical framework constructed through multiple relations and inserted in the social context.

Theoretical reflections will lead to identifying which design tools can be useful to support the various forms of innovation.

The research and the teaching are increasingly tending to converge, creating forms of exploratory learning. The educational model starts from an as- sumption: take advantages from technological innovations arising by the use of new technologies and the result of ongoing research in order to let the products and services meet today's social issues.

Future designers have to learn to be careful observers of the socio cultural context of which they are central players, in order to be, in the coming decades, proactive actors in the economy. During the training the teacher should provide students with the tools which are useful to read the context and should suggest innovative scenarios that are real answers to social/user needs and strategic in addressing the future challenges. The design process should have a pure application. Scientific basics, which are the result of applied research, overlap onto a theoretical framework in order to build basic knowledge useful for the designer's approach to the design of new devices.

Within this new context, there is the need to arrange a new educational model from which design can create relevant answers and confront itself with the complexity of modern scenarios.

This paper reports on the model used for the sixth year Final Synthesis Design Studio (FSDS) course at the Politecnico di Milano.

The FSDS uses an innovative educational model for design: during the course the knowledge and experience of the professors become part of the student's hands-on designing [9]. Each project is a new challenge not only for the students, but also for the team of teachers, since it represents a new research field and testing ground.

Through constant interaction with the professors (and in turn their different knowledge backgrounds and personalities) the students learn to see their own work from different angles, making it easier to identify any possible problems and to make better choices in developing their design ideas. This then aids their personal maturity in defining their own design process.

With this educational model the student becomes familiar with the current professional model where a constant interaction within the design team is integral part of the work. The designer has to keep the dialogue open between various professional figures e.g. the managing director, the technical director, the marketing manager, the Research and Development department, the printing office, the suppliers and, when possible, the specific users of the products.

In a similar way when a designer presents its final project it would not only be in front of the single "enlightened business man", but often, in front of a panel of directors of various departments, each of them 
with their own goals and more than likely from opposing positions.

Through years of experience, we have come to realize how essential it is for students to learn how to be able to achieve a satisfactory compromise with the team of teachers as a way to train the student's abilities to interact with the different figures involved throughout the development of a product.

It is extremely important for a young designer to contribute to the reconfiguration of the relation product/user according to the needs of the ever more fluid and flexible markets and societies. Identifying needs, desires and behaviors together with user experience are crucial elements for developing high quality products and services. "In the near future, designers will learn to use their own creativity to amplify the creativity of everyday people" $[15,16]$. Today, more than ever, arises the need for a methodological approach able to consider, in a comprehensive way, the context of use, involving the "creative abilities" of the user. From this perspective, to introduce simple exercises enabling students to build their own tools to involve users during the creative phase, gives them the chance to understand the value of delineating new design strategies.

From a didactic point of view the main aim is to teach a method, to be applied during the different design phases, able to support a young designer in the understanding of people's needs and desires not only on the physical and cognitive level, but on the emotional level as well.

The ability of a product to interpret and meet the needs of people's psychological and perceptive spheres, is linked, then, to different factors such as: expectations, desires and aesthetics as separate from social, cultural and generational references. These constitute a research area particularly relevant to design and which identifies new values for the design of everyday objects, a clear evolution from a business model driven exclusively by market needs to a design-driven one [13].

\section{From the brief to the final project}

The design process begins with a company giving the designer a brief. From that brief, the designer then submits their different proposals or concepts to the company. The concept that is most in line with the philosophy and needs of the brand is chosen and developed through test models, virtual models and inspections until the final version is approved.
During the Final Synthesis Design Studio course we give the students an added challenge. As the team of teachers doesn't assign a well-defined brief, but only chooses a category of products, each student has to undertake an analysis process in order to choose the product/issue he is going to focus on and develop their own framework for the project.

There are several reasons why we ask our students to develop the definition of their own brief. Firstly, this project will be their final thesis (they will work on it for a full year) so we believe it is important to let them choose a product they are more involved and interested in

Secondly the designer should not only be a creative expert, capable of applying good taste by designing quality products, but also a professional (whether designer, architect, engineer, etc.) aware of the ethical consequences of his work. To learn how to structure and think about the requirements of a product, helps the student to both become conscious of various ethical issues such as eco-compatibility, material and energy consumption reduction and understand the real user's needs. In a society over floated by products there is no need to design if we cannot go beyond a simple new shape and give the product a real surplus value that can help the performances and increase the well-being of its user.

The third reason relates to the second but also comes from a strategic point of view. Focusing on the issues related specifically to the category of the product to be developed, the designer develops a better understanding of the unexplored areas within the market. For example the specific needs of differentiated targets groups, conditions of use in different contexts, difficulties in physical or cognitive interaction etc. The requirements of the product are then expanded in order to satisfy previously unaddressed needs.

This process sees the students carrying out an introductory analysis in order to define, and better understand, their own brief before starting the design process. It is important to understand that the course is characterized by an ergonomic approach to design as we believe being unthinkable to design something without considering the context the product will fit in and the network it will generate between the different users that will interact with it. The methodological approach that is used in the course is based on User Centred Design (UCD).

The course is made up of three main stages:

1. Analysis: developing a research method focused on defining the brief and the design requirements. 
2. Concept: the design goals start "coming to life" in the new ideas: the concepts.

3. Final project: the concepts are developed to an executive standard, bearing in mind the technical and production constraints.

The educational model makes use of three different modes of teaching:

- theoretical/methodological lectures, given by each teacher of the laboratory, according to his own field of expertise. The lectures are organized in relation to specific moments during the design process;

- seminars with professionals, companies or experts with multidisciplinary skills in order to provide the students with a wider view of the design issues;

- tutoring activities - revision of the projects. Students work in the classroom while the teachers and tutors help them in developing their design process thanks to systematic revisions. This is the most important module as it is when the learning becomes practice.

The students' design process is not linear and the method proposed is meant to give the students the stimulus to expand and constantly reassess their work. The model is therefore not just consecutive but interactive, as it builds on the students' experiments as they inspects and fine tune their designs according to the their learning level and the ability to focus on specific issues.

Each step ends with a presentation to the class and an evaluation by the teachers' team.

Therefore the students become familiar with presenting and promote their ideas and projects to a general public and a wider audience.

\section{The didactic modules}

The following scheme represents the modules and the didactic content given to the students in order to support them with a methodological approach throughout the entire process.

The teaching team counts on Politecnico's professors and external experts in order to keep a strong contact with the real context and in particular, with companies. The goal of the course is to teach a design process not only on an educational/didactic level, but also as a real comparison with the real market, made of needs and concrete constraints. It is clear to see that the most theoretical contributions given by the team are concentrated in the analysis module.
Figure 1

Scheme of the 5 phases in the design process [1].

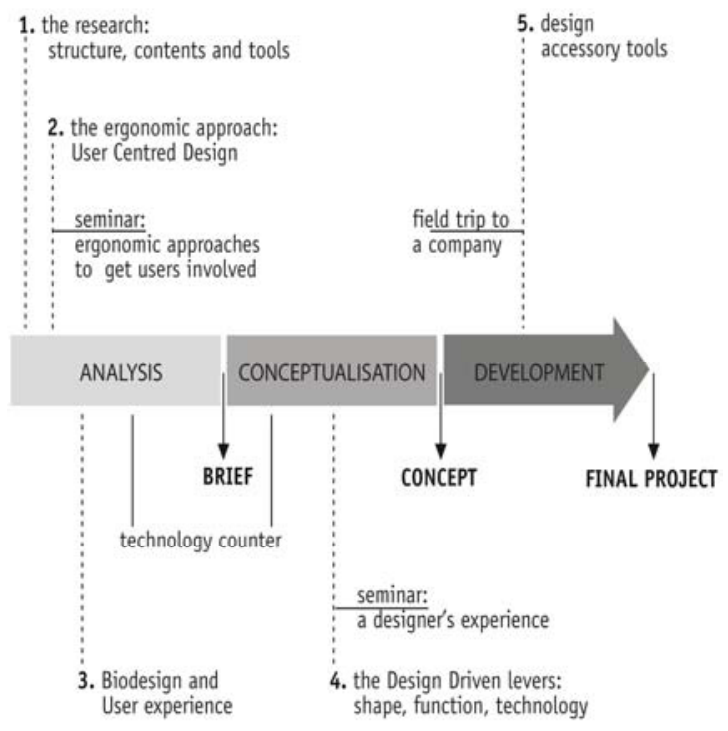

This allows the students to gain the skills and methods they need to expand their horizons and work on the design issues as quickly as possible. After the analysis, in the following steps, less time is spent on learning from lectures and more time is spent in hands-on activities.

Follows a brief overview of the course divided into design process:

Module 1 aims at defining the design process approach, i.e. which areas to research and which tools to use. This is the basis of the students work since it supplies them with a scientific method to approach their research and gain the necessary information. The first step gives the students the skills to structure their preliminary research: choosing the context, historical references, benchmarking, the state of the art material and technologies; but also everything that concerns the use analysis: the target users, the conditions of use and possible competitors.

Module 2 follows with the contribution of the ergonomic approach. In this module users' direct involvement suggested by the UCD helps the students to understand the psycho-physical and emotional interaction between the user and the product. Follows the understanding of their needs, desires, difficulties, etc. The seminar with a psychologist (during module 2) teaches the students the ergonomic methodologies and the investigation techniques used professionally to get users involved. 
Students are encouraged to carry out trials with users and compare a range of products, similar to the one to be redesigned. The idea is to involve users from different backgrounds in a typical context of use of the product in order to highlight possible design directions. Interviewed users are not usually involved in the concept and design phases due to didactic timing, but are involved in the final phase of the product development, when usability is tested using mock-ups.

Module 3 is based on biodesign experiences that connect the human body, conceived as a psychobiological unicum, and the advanced technologies. The relationship between the user's needs and the design is very important in this phase and requires active planning and consideration.

It also involves the users groups with interviews, questionnaires, direct observations, etc. This underlines both the issues involved as well as the specific aims of the final product.

Module 4 begins at this stage. This module stimulates the students creativity working on analogies and brainstorming techniques: suddenly a chupa-chup (Fig. 2) or a jar could become an aerosol (Fig. 3), etc.. Figure 2

Analogy between the "chupa chups" and the thermometer Chupa-ti by R. Pellizzi

Part to be introduced into the mouth

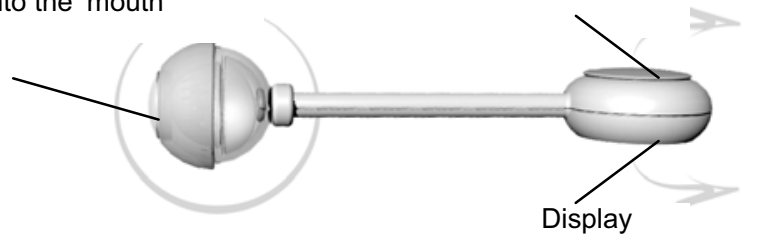

Figure 3

Analogy between a jar and the aerosol Tin-O2 by F. Piccinini

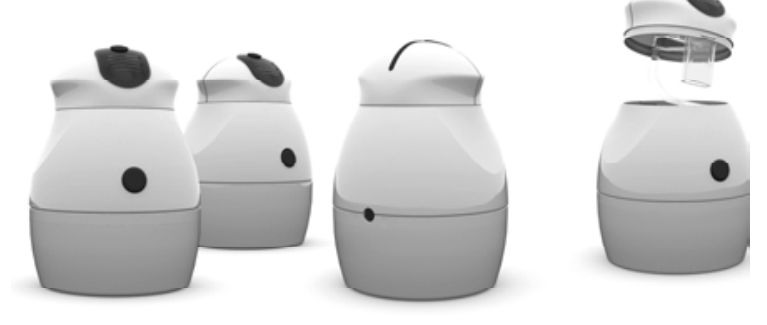

This educational method includes the teaching, through lectures, of some of the tools designed and used by leading design firms such as IDEO, Design Continuum, Philips Design, and an experimentation phase through short class exercises of the basic techniques.

The didactic approach takes the definition of creativity as its point of departure along with the valorization of lateral thinking followed by a description of the tools related with the different phases of the design process. Due to the quality of existing techniques and the inexperience of the students, two or three of the most interesting techniques are presented for each phase of the design process during a dedicated lecture.

In the same module the Design Driven levers are introduced: shape, function, technology and a particular examination of the problems related to the function and the possible ways of use.

During the phases of analysis and concept development, we also activate the Technology Counter that helps the students select materials and technologies for their design. Again, the learning is not only theoretical but it counts on the use of the new knowledge gained from specific needs or awareness of constraints (costs, time, practicality, compatibility with the rest of the project, technology appropriate for the materials, shape, dimensions, finishes, etc.).

To better support the students with these design obstructions, we organize a field trip to an appropriate company. Here the students are able to learn in a strait forward way what is a cast, a press, how injection moulding works, the different techniques to work on metals, etc. During this phase we believe that learning on field is more informative than a normal classroom lecture.

During module 5 (executive development of the product) the teachers, assisted by an external professional, help the students to find their way from the concept stage to the executive project through close inspection of preparatory models and technical drawings.

\section{Creativity tools}

One of the methods to involve people in the design process is certainly the game. Both Philips and IDEO have developed kits enabling the designer to approach the creative phase in a dynamic and engaging way. Philips Design [20] has developed "Spark", a game to stimulate creativity and innovative thinking. IDEO Method Cards is a collection of 51 cards [10] representing diverse ways used by design teams to understand the people they are designing for. 
During Module 4 a class workshop [5, 6] aimed at teaching students how to build their own tools to facilitate user's involvement is presented.

The learning scheme adopted relies on the three following phases: representation of conduced analysis; problem identification; preparation of tools to support the brainstorming session.

The students are asked to produce a number of cards, able to stimulate the generation of ideas, to be used during a simulated brainstorming session. The material made to support the experimentation is devoted to knowledge-elicitation-tools such as card sorting and brainstorming. During the class exercise, groups are organized in macro-groups of 12 people where each design team (of three people) is charged with the organization and presentation of the material for the creative session to the colleagues. The exercise is organized over three days. The first day, the preparation of the creative session, starts form the graphic interpretation of the information collected and the definition of the problem to be explored during the activity. The leading group would have 10 minutes (max.) to introduce synthetically the topic. Students are invited to use mental maps. A map is a highly effective tool of abstraction and mental organization, it enables students to articulate, organize and structure information, thus supporting and easing creative thinking.

Figure 5

Mind map of problems involved in asthma

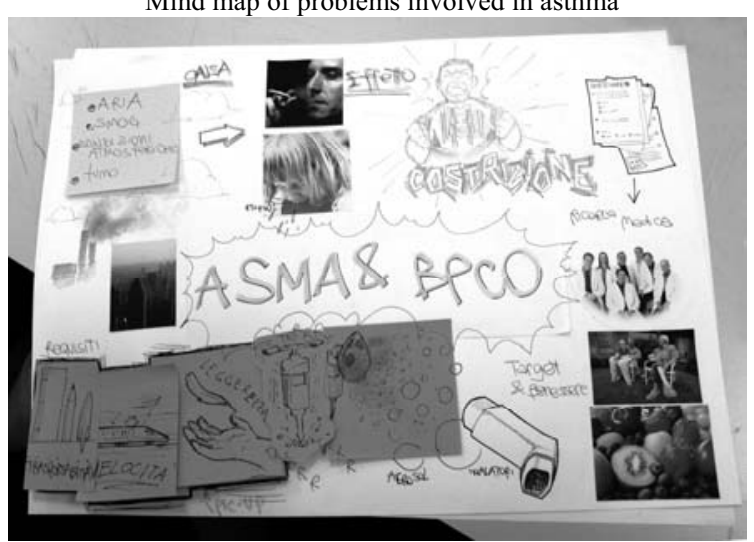

After the completion of the formalization of the aspirations and visualization of the issues and/or requirements starts the production of the cards based on the IDEO model. The cards are classified as four suits: Ask - recruit people to have information useful for the project; Look - observe people to understand what they really do instead of believing what they say they do; Learn - analyze collected information to identify models and possible intuitions; Try - simu- late activities to try and identify with people and evaluate suggestions or possible design directions. Students are asked to produce at least one for each kind and encouraged to make some more for Try.

Each student has set up 4 cards (one for each category) in order to collect specific information in relation to the project and the direct observations hypothesized (particular actions or experiments intended to be tested with the user). Obviously, the cards are built on previously gathered information related to the design to be developed. Each card should have a short text explaining How and Why as well as an evocative image.

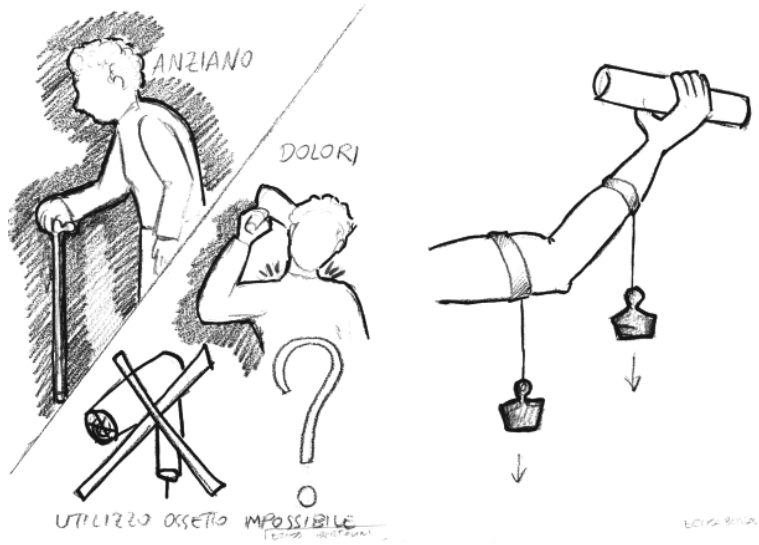

Figure 6

Sketches for Learn and Try cards (up) and their final images (by E. Bertolini)
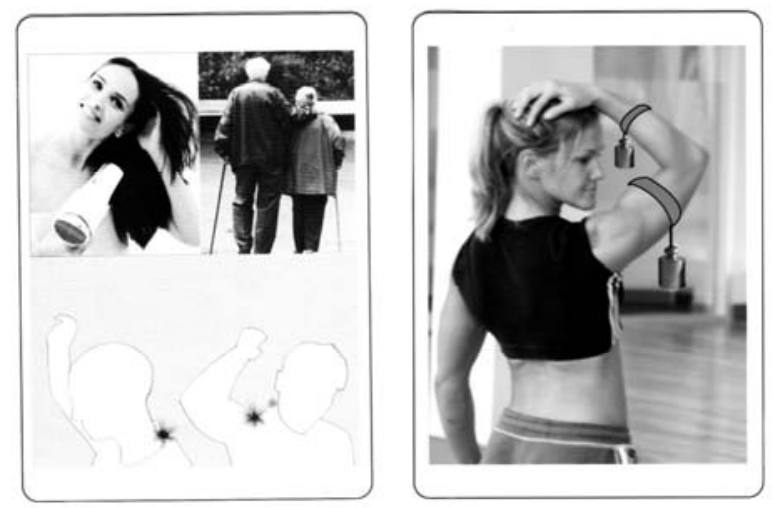

The last phase of the workshop is the simulation of the brainstorming. Starting from the meaning of the word brainstorming "brain storm", the students are reminded that ideas are generated as a consequence of each other. The starting point would be the design issue followed by a free flow of more or less possible solutions and ideas. 
The group leading the brainstorming session should stimulate the others to propose ideas and write them down using key words. The creative exercise takes place simultaneously for $3 / 4$ macro-groups. After the 10 minutes dedicated to the initial description of the issue every design team has an hour to carry out the activity and use the cards and the tools previously produced for such purpose.

\section{Conclusion}

This teaching model proposed is very challenging and full of activities for the students. The teacher's multidisciplinary skills, combined with a User Centred Design approach (requiring students to interact directly with the users and get them actively involved) give way to a radical change. In a world overwhelmed by products becoming obsolete in a short time, teaching a method developed on real needs without inducing others, promotes an ethical approach to design.

From a linear process made of consequential stages we move on to an iterative cycle that requires evaluations and inspections with users in order to move on to the next step. The students learn a process and show their interest in using the UCD methods, when defining and managing focus groups, questionnaires for the users, and other tools that might be useful for them in other courses as well.

This approach first of all enables the student to investigate users' needs and desires; secondly it helps them proposing innovative ideas and projects more aware of what's already available on the market. The students' feedback has been very positive. The results collected in the evaluation questionnaires about the didactic activities (Program of evaluation of the didactic activity - Law 370/1999) have proven the high interest and attention given by the student to such educational model.

During the presentations of Bachelor degree thesis, the Commissions composed by teachers and professionals have always appreciated the high quality of the projects submitted.

A patent, for example, now protects one of the students' projects and often companies have shown great interest in developing students' projects to possibly start producing them. A detailed description of this educational model, together with the contributions of the professors involved and a series of final projects, developed by students on domestic medical devices, have been published in a book [1].

\section{References}

[1] Anselmi L., Il Design di prodotto oggi, FrancoAngeli, Milano, 2009.

[2] Bürdek B.E., Design: History, Theory and Practice of Product Design, Birkhauser, Basel, 2004.

[3] Commission Communication 'Putting knowledge into practice: A broad-based innovation strategy for the EU' of 13 September 2006 COM(2006)502.

[4] Commission Staff Working Document, Design as a driver of user-centred innovation, Brussels, 7.4.2009 SEC(2009)501

[5] Canina M., Coccioni E., Creating a Participatory Design Tools: Didactic Experience, Proc. of the International Conference on Research into Design (ICoRD '11), Indian Institute of Science, Bangalore, India, 10-12 January 2011.

[6] Canina M., Anselmi L., Coccioni E., Designing with Users: a Teaching Model, the 4th World Conference on Design Research, Delft University of Technology, Netherlands, October 31 - November 42011.

[7] De Bono E., Lateral thinking. A textbook of creativity, BUR, 1998.

[8] Green J. "Democratizing the future. Towards a new era of creativity and growth", IIT Institute of Design Strategy Conference, Chicago, Illinois, 2008.

[9] IDEO, Fivesteps in the process of designing a better customer experience, www.ideo.com

[10]IDEO Method

Cards, http://www.ideo.com/work/item/method-cards

[11] Mendonca L.T., Rao H., "Lessons from innovation's front line: an inter-view with IDEO's CEO”, McKinsey Quarterly, November, 2008.

[12] Norman D.A., Emotional Design, Apogeo, Milano, 2004.

[13] Nussbaum B., "The power of design", Business Week, McGraw-Hill, New York, 2004.

[14]Penati A., Seassaro A., Didattica\&Design, POLI.design, Milano, 2000.

[15] Sanders E., Chan P., "Emerging Trends in Design Research", International Association of Societies of Design Research (IASDR07), The Hong Kong Polytechnic University, 2007.

[16] Sanders E., "Design Serving People", Salmi, E., Anusionwu, L. (by), Cumulus Working Papers, Copenhagen, University of Art and Design, Helsinki, Finland, 2006.

[17] Sanders E., Stappers P.J, "Co-creation and the new landscapes of design", CoDesign, Taylor \& Francis, March 2008. Available http://journalsonline.tandf.co.uk

[18] Sanders E., "From User-Centered to Participatory Design Approaches", In J. Frascara (a cura di), Design and the Social Sciences, Taylor \& Francis Books Limited, London, 2002

[19] Testa A., Theory and practice of creativity. The meaning of creativity. http://www.nuovoeutile.com/en-creativity.htm

[20]Philips Design (2009), Playful innovation, Available on: http://www.design.philips.com 